\title{
Correlação entre os marcadores tumorais CEA e CA 72-4 e a profundidade de invasão no câncer gástrico
}

\author{
Correlation between tumor markers CEA and CA 72-4 and depth of \\ invasion in gastric cancer
}

\author{
Flávio Daniel Saavedra Tomasich', Viviane Coimbra Augusto², Murilo de Almeida Luz ${ }^{3}$, \\ Luiz Antonio Negrão Dias ${ }^{4}$ e Massakazu Kato ${ }^{5}$
}

\section{Resumo}

O bjetivo: avaliar a correlação entre o nível sérico do CEA e CA 72-4 com a profundidade de invasão e estadiamento das neoplasias gástricas.

$M$ aterial e M étodos: foram avaliados pacientes com adenocarcinoma gástrico admitidos no Serviço de Cirurgia Abdominal do H ospital Erasto Gaertner no período de janeiro de 1996 a janeiro de 2000, incluindo-se neste estudo os pacientes que apresentavam dosagem sérica pré e pós-operatória de pelo menos um dos marcadores (CEA e/ou CA 72-4) e apresentavam estadiamento patológico ou evidências de doença disseminada pelos métodos de imagem. Resultados: dos 144 pacientes elegíveis, 71\% eram do sexo masculino. A média de idade foi de 59 anos. 0 CEA mostrou-se alterado em $66,2 \%$ dos casos, e em $70,3 \%$ dos casos na análise do CA 72-4. Q uanto à profundidade de invasão, o tumor invadia até a camada mucosa em apenas sete $(4,8 \%)$ pacientes, até a camada submucosa em oito $(5,6 \%)$ pacientes, muscular em 34 (23,6\%), serosa em 45 (31,3\%) e órgãos adjacentes em 33 (22,9\%) dos casos. Em 17 pacientes a profundidade de invasão não foi avaliável, embora já fosse definida a doença como disseminada por outros meios. $\mathrm{N}$ a análise comparativa dos níveis séricos do CEA e do CA 72-4, de acordo com a profundidade de invasão, não observamos significância estatística para positividade dos marcadores nos tumores gástricos.

Conclusões: no presente estudo, os marcadores séricos CEA e CA 72-4 não se mostraram como fatores preditivos para profundidade de invasão e estadiamento nos pacientes com câncer gástrico.

Palavras-chave: neoplasias gástricas; marcadores biológicos de tumor; invasividade neoplásica; prognóstico; estadiamento de neoplasias; antígeno CEA; antígeno CA 72-4.

IM édico Titular do Serviço de Cirurgia A bdominal do $\mathrm{H}$ ospital Erasto $\mathrm{G}$ aertner.

${ }^{2}$ M édica Residente em Cirurgia O ncológica do H ospital Erasto G aertner. Enviar correspondência para V.C.A. Serviço de Cirurgia Abdominal do H ospital Erasto G aertner, Rua D r. 0 vande do Amaral 201; 81520-060 Curitiba, PR - Brasil. E-mail: cepep@lpccnet.org.br

${ }^{3}$ A cadêmico Interno do H ospital Erasto G aertner.

${ }^{4} \mathrm{M}$ édico Titular do Serviço de Cirurgia Abdominal do H ospital Erasto G aertner.

${ }^{5} \mathrm{C}$ hefe do Serviço de Cirurgia Abdominal do $\mathrm{H}$ ospital E rasto $\mathrm{G}$ aertner.

Recebido em maio de 2001. 


\begin{abstract}
Background: the authors evaluated the correlation between the seric level of CEA and CA 72-4 to the depth of invasion and staging of gastric neoplasms.

M ethods: were evaluated patients with gastric adenocarcinoma admitted at the Department of Abdominal Surgery, Erasto Gaertner H ospital, in the period between January 1996 and January 2000 , including in this study patients who had preoperative and postoperative dosage of at least one of thetumor markers (CEA and/or CA 72-4) and had pathologic staging or evidences of disseminated di sease by image methods.

Results: of the 144 eligible patients, $71 \%$ were male. The mean age was 59 years. CEA was altered in $66,2 \%$ of the cases, and in $70,3 \%$ of the cases for CA 72-4 analysis. Regarding depth of invasion, tumor invaded mucosal layer in $7(4,8 \%)$ patients, submucosal layer in $8(5,6 \%)$ patients, muscular layer in $34(23,6 \%)$, serosa in $45(31,3 \%)$ and adjacent structures in $33(22,9 \%)$ of the cases In 17 patients the depth of invasion was not available, although disseminated disease was al ready confirmed by other methods. In the comparative analysis of seric levels of CEA and CA 724 related to depth of invasion, we did not observe statistic significance to positivity rates of markers in gastric tumors.

Conclusions: in this study, the CEA and CA 72-4 did not predict depth of invasion and staging in patients with gastric cancer.
\end{abstract}

Key words: stomach neoplasms; biological tumor markers; neoplasm invasiveness; prognostic; neoplasm staging; CEA antigen; CA 72-4 antigen.

\section{INTRODUÇÃO}

Apesar do progresso no tratamento do câncer gástrico, ainda não foram estabelecidos marcadores tumorais que possam definir o prognóstico cirúrgico dos tumores avançados. ${ }^{1}$ D esde sua detecção em 1965, por Goldman e Freedman, ${ }^{2} 0$ antígeno carcinoembriogênico (CEA) tem sido alvo de pesquisas tentando definir sua real importância nas várias fases dos tumores do trato gastrintestinal. Análises multivariadas já definiram este marcador como fator prognóstico isolado, bem como para metástases hepáticas em pacientes com tumores em estádio IV. ${ }^{2}$ Embora não tenha correspondido às expectativas iniciais, o CEA foi tomando importância de acordo com a experiência de cada serviço de oncologia, sendo os valores de corte atualmente entre 2,5 e 5,0 $\mathrm{ng} / \mathrm{ml} .^{3} \mathrm{~N}$ a busca por um melhor marcador para os tumores gástricos, alguns estudos demonstraram a importância do antígeno de carboidrato 72-4 (CA 72-4), com boa especificidade em tumores gástricos e candidato a marcador ideal. ${ }^{4,5}$ Já foi sugerida a combinação entre o CEA e o CA 72-4 como a de melhor fator preditivo positivo em pacientes com câncer gástrico. ${ }^{6}$ Este estudo compara os níveis séricos dos marcadores tumorais CEA eCA 72-4 com a profundidade de invasão em 162 casos de tumores gástricos, procurando avaliar a validade destes marcadores como preditivos do prognóstico cirúrgico destes pacientes.

\section{MATERIAL E MÉTODOS}

Foram avaliados retrospectivamente 570 prontuários de pacientes portadores de neoplasia gástrica maligna, atendidos no Serviço de Cirurgia Abdominal do H ospital Erasto Gaertner no período de janeiro de 1996 a janeiro de 2000. Foram incluídos neste estudo os pacientes com adenocarcinoma gástrico que apresentavam dosagem sérica pré e pósoperatória de pelo menos um dos marcadores (CEA e/ou CA 72-4) e apresentavam estadiamento patológico ou evidências de 
doença disseminada pelos métodos de imagem. Foram excluídos pacientes com história pregressa de outra neoplasia, que haviam sido submetidos a cirurgias de ressecção em outro serviço ou ainda possuíam dados incompletos nos prontuários. U m total de 144 pacientes preencheram os critérios que puderam ser utilizados nas análises, onde foram avaliadas as seguintes variáveis: idade, sexo, características anatomopatológicas, classificação de Bormann e Laurén, tratamento cirúrgico, radioterápico e/ou quimioterápico, ressecabilidade tumoral e estadiamento. A dosagem sérica dos marcadores tumorais CEA e CA 72-4 foi realizada na admissão e após a cirurgia.

0 ponto de corte para o CEA foi de 5,0 $\mathrm{ng} / \mathrm{ml}$ e de $6,0 \mathrm{U} / \mathrm{ml}$ para o CA $72-4$, sendo consideradas alteradas todas as dosagens acima destes valores.

Os dados foram submetidos à análise estatística descritiva e específica para cada variável, além de análise univariada através do teste de Q ui-quadrado ou teste exato de Fischer conforme a necessidade.

\section{RESULTADOS}

A média de idade dos pacientes estudados foi de 59 anos, variando de 28 a 81 anos. A maioria dos pacientes $(71 \%)$ era do sexo masculino.

O carcinoma avançado correspondeu a mais de $77 \%$ da população incluída neste estudo (Figura 1).

Q uando se comparou a dosagem sérica dos marcadores tumorais no pré e no pósoperatório, observou-se que $68,2 \%$ dos pacientes tinham CEA alterado no préoperatório, enquanto $31,8 \%$ apresentavam níveis considerados normais, conforme 0 ponto de corte estabelecido como 5,0 ng/ml. $\mathrm{N}$ o pós-operatório, o percentual de CEA alterado foi de $25 \%$, o que foi estatisticamente significante com $p=0,0071$. O CA 72-4 mostrou-se alterado $(>6,0 \mathrm{U} / \mathrm{ml})$ em $72,5 \%$ dos pacientes no pré-operatório e em $27,5 \%$ no pós-operatório, o que também foi estatisticamente significante, com $p=0,0053$. (Figuras 2 e 3 )

Em relação ao estádio clínico (EC), conforme o estadiamento da UICC (1998),
$59 \%$ dos pacientes eram EC IV, sendo 0 restante distribuídos uniformemente entre os EC I $(12,1 \%)$, II $(15,7 \%)$ e III $(13,2 \%)$.

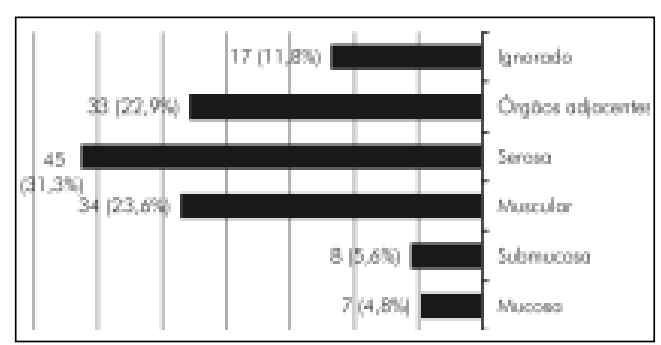

Figura 1. Distribuição do grupo estudado conforme a profundidade de invasão

$\mathrm{N}$ a análise comparativa dos níveis séricos do CEA e do CA 72-4, de acordo com a profundidade de invasão, não observamos significância estatística para positividade dos marcadores nos tumores avançados (Tabela 1). Essa significância também não foi observada quando se comparou separadamente a profundidade de invasão (mucosa, submucosa, muscular e serosa) com a positividade dos marcadores.

Quando se avaliou a presença de carcinomatose peritoneal, observou-se positividade do CEA nos pacientes com carcinomatose em $76,2 \%$ e do CA $72-4$ em $72,3 \%$, não tendo sido significante a diferença em relação ao grupo sem carcinomatose $(p=0,134$ e 0,29 , respectivamente). (Figuras 4 e 5$)$

As demais variáveis analisadas: idade, grau de diferenciação celular, localização do tumor, classificação de Bormann e Laurén, profundidade de invasão e tamanho do tumor, assim como presença de metástase linfonodais, disseminação sistêmica, estádio clínico, tipo de tratamento cirúrgico realizado e ressecabilidade do tumor não tiveram significância com os testes estatísticos aplicados.

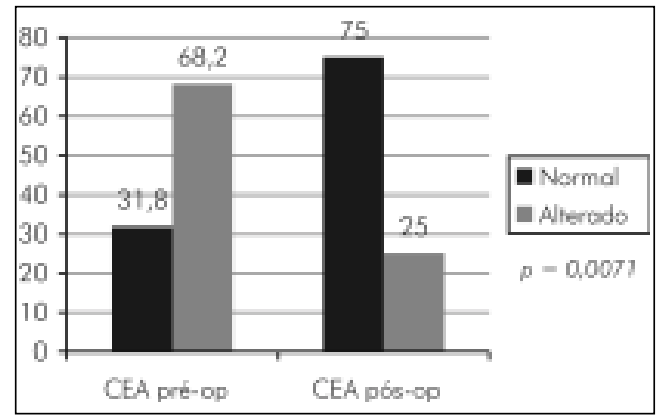

Figura 2. Comparação entre os níveis séricos do CEA pré e pós-operatório 


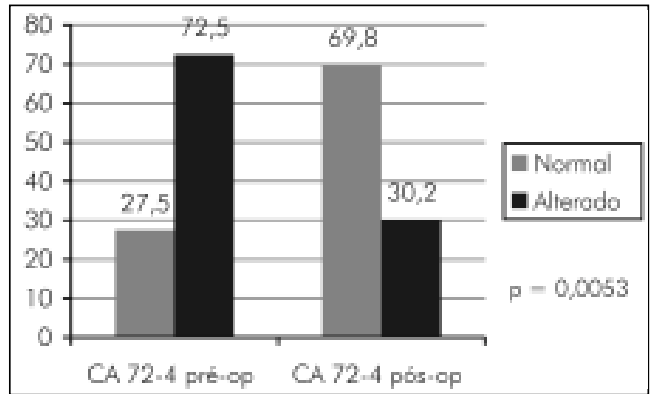

Figura 3. Comparação entre os níveis séricos do CA 72-4 pré e pós-operatório

\section{DISCUSSÃO}

As três principais funções de um marcador para o câncer gástrico seriam a detecção precoce, a avaliação do prognóstico cirúrgico e o monitoramento de possíveis recorrências. Atualmente, 0 uso é restrito basicamente ao acompanhamento pósoperatório. ${ }^{6}$ Ainda existem divergências e controvérsias sobre a real importância de marcadores como o CEA e o CA 72-4 na quantificação da evolução do câncer gástrico. ${ }^{7}$ A taxa de positividade pré-operatória do CEA tem sido relatada entre 11,8 e $37 \%, 7,8$ sendo que encontramos grande positividade nesta amostra $(66,2 \%)$ o que em parte se explica por pequena parte da amostra se compor de pacientes em estádio I. Para o CA 72-4, alguns estudos definiram taxas de sensibilidade entre $40-50 \%$, embora com especificidade próxima de $100 \% \cdot{ }^{4} \mathrm{~N}$ ovamente encontramos positividade bem mais expressiva (70,3\%). Um dos pontos mais importantes em relação à análise comparativa das séries histórica é a grande variância nos pontos de corte, com intervalos entre 4,5 e $6,7 \mathrm{ng} / \mathrm{ml}$ para $0 \mathrm{CA}$ $72-4^{4,9}$ e 2,5 e 6,0 para o CEA ${ }^{8-10}$

Assim como neste estudo, muitos autores definiram como não significante a diferença no número de pacientes com os marcadores alterados ao ser avaliado cada estadiamento em específico ${ }^{8,9}$ Apesar disto, já foi demonstrada a maior positividade do CEA e do CA 72-4 ao comparar-se estadiamentos I e II com III e IV agrupados ${ }^{9-11}$ ou apenas pacientes com estádio IV comparados aos demais. ${ }^{7,8}$

Poucos comparam a positividade dos marcadores com a profundidade de invasão tumoral. J oypaul et al. ${ }^{4}$ encontraram diferença entre a média dos níveis séricos do CA 72-4 comparando tumores precoces e avançados. $\mathrm{N}$ a presente amostra não ficou demonstrada significância estatística para a diferença no número de pacientes com marcadores tumorais alterados em relação à profundidade de invasão, ao compararmos tumores restritos à mucosa ou progressivamente à submucosa, muscular, serosa ou órgãos adjacentes. Também não houve diferença estatística ao compararmos tumores precoces e avançados em relação à positividade dos marcadores, embora como já citado, poucos eram os casos de tumores precoces $(10,4 \%)$.

Tabela 1. Comparação de positividade do CEA e do CA 72-4 de acordo com a profundidade de invasão tumoral (precoce e avançado)

\begin{tabular}{lcccccc} 
& \multicolumn{3}{c}{ CEA } & & \multicolumn{3}{c}{ CA 72-4 } \\
\cline { 2 - 7 } & Negativo & Positivo & Valor p & Negativo & Positivo & Valor p \\
& $(\%)$ & $(\%)$ & & $(\%)$ & $(\%)$ & \\
Carcinoma precoce & 24,24 & 75,76 & NS & 26,67 & 73,33 & NS \\
Carcinoma avançado & 34,73 & 75,27 & & 29,63 & 70,37 & \\
\hline
\end{tabular}

O s estudos de $\mathrm{N}$ akane et al.,12 Tachibana et al. ${ }^{7}$ e K odera et al. ${ }^{11}$ demonstram diferença estatística quando compararam a alteração nos níveis dos marcadores tumorais com a profundidade de invasão do câncer gástrico.

N um estudo com 153 pacientes submetidos a ressecção por câncer gástrico, $\mathrm{M}$ arelli et al. ${ }^{13}$ encontrou correlação da positividade do CEA com a profundidade de invasão e a presença de metástases à distância, enquanto a positividade do CA 72-4 correlacionou-se com o tamanho do tumor e com cirurgia não-curativa. A positividade de ambos marcadores foi associada a pior prognóstico quando comparada com os casos onde os marcadores eram negativos.

Ishigami et al. ${ }^{14}$ só puderam determinar significância para a positividade do CEA em relação à profundidade de invasão quando dobrou o valor de corte para $10 \mathrm{ng} / \mathrm{ml}$.

$\mathrm{Kim}$ et al. ${ }^{15}$ encontraram significância estatística da profundidade de invasão em relação ao CEA, tanto quando avaliou a positividade do marcador (CEA >5,0 $\mathrm{ng} / \mathrm{ml}$ ), como quando estratificou em valores menores que 5,0 ng/ml, entre 5,0 e 10,0 ng/ml e acima de $10,0 \mathrm{ng} / \mathrm{ml}$. 


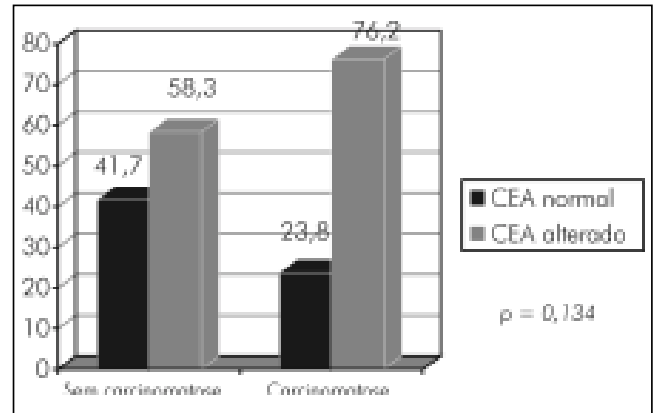

Figura 4. Positividade do CEA em pacientes com e sem carcinomatose peritoneal

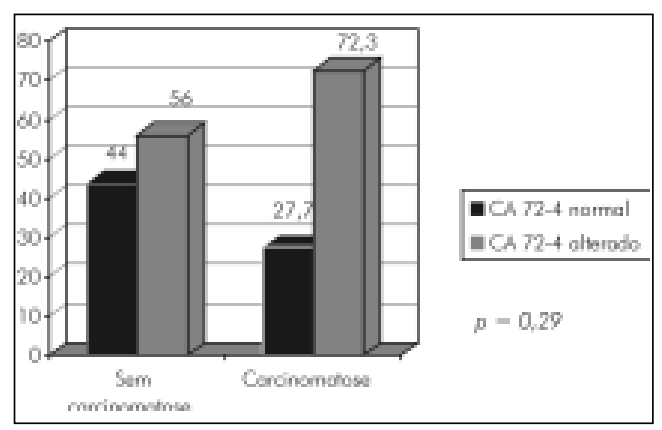

Figura 5. Positividade do CA 72-4 em pacientes com e sem carcinomatose peritoneal

Ao comparar a dosagem do CEA no sangue periférico e no sangue venoso da drenagem gástrica, Imada et al. ${ }^{16}$ determinaram correlação entre as taxas do marcador do sangue periférico e a profundidade de invasão, detectando a presença do marcador na drenagem venosa gástrica apenas em tumores que atingiam a serosa ou órgãos adjacentes.

H ouve diferença expressiva no número de pacientes com marcadores alterados ao serem comparados grupos com ou sem carcinomatose, com elevação nos níveis séricos naqueles pacientes portadores de carcinomatose peritoneal, embora análise estatística não confirme esta variável como significante.

\section{CONCLUSÃO}

No presente estudo, não se observou correlação entre a profundidade de invasão tumoral e estadiamento e os níveis séricos do CEA e CA 72-4 em paciente com câncer gástrico.

Como algumas séries de outros autores puderam determinar positividade crescente dos marcadores com 0 aumento da profundidade tumoral, embora esse achado não seja consenso na literatura, mais estudos se fazem necessários para consolidar essa correlação.

\section{REFERÊNCIAS BIBLIOGRÁFICAS}

1. Asao T, Fukuda T, Yazawa S, N agamachi Y. $C$ arcinoembryonic antigen levels in peritoneal washingscan predict peritoneal recurrence after curative resection of gastric cancer. Cancer 1991;68:44-7.

2. Ikeda Y, M ori M, Kajiyama K, Kamakura T, $M$ aeharaY, $H$ araguchi Y, Sugimachi K . Indicative value of carcinoembryonic antigen (CEA) for liver recurrencefollowing curativeresection of stagell and III gastric cancer. H epatogastroenterology 1996;43:1282-7.

3. SikorskaH , Shuster J, Gold P. C linical applications of carcinoembryonic antigen. $C$ ancer D etect Prev 1988;12:321-55.

4. Joypaul B, Browning $M, N$ ewman $E$, Byrne $D$, Cuschieri A. Comparison of serum CA 724 and CA 19-9 levels in gastric cancer patients and correlation with recurrence. Am J Surg 1995;169:595-9.

5. Fernández-Fernández $L$, Tejero $E$, Rabadán $L$, Tieso A, M uñoz M , SantosI. Receiver operating characteristic (ROC) curve analysis of tumor markers CEA, CA 19-9 and CA 72-4 in gastric cancer. Int Surg 1996;81:400-2.

6. Kodama I, Koufuji K, Kawabata S, Tetsu S, Tsuji Y, TakedaJ, KakegawaT. Theclinical efficacy of CA 72-4 as a serum marker for gastric cancer in comparison with CA 19-9 and CEA. Int Surg 1995;80:45-8.

7. Tachibana $M$, Takemoto $Y, N$ akashima $Y$, Kinugasa S, Kotoh T, D har D K, Kohno H, $N$ agasueN . Serum carcinoembryonic antigen as a prognostic factor in resectable gastric cancer. J Am C oll Surg 1998;187:64-8.

8. Janssen $\mathrm{CW}, \varnothing$ rjasater $\mathrm{H}$. C arcinoembryonic antigen in patientswith gastric carcinoma. Eur J Surg O ncol 1986;12:19-23.

9. Grem J. The prognostic importance of tumor markersin adenocarcinomas of thegastrointestinal tract. Curr O pin O ncol 1997;9:380-7.

10. Cooper M J, M ackieCR, Skinner D B, M oosaAR. A reappraisal of thevalue of carcinoembryonic antigen in themanagement of patients with various neoplasms. BrJ Surg 1979;66:120-3.

11. Kodera Y, Yamamura Y, Torii A, U esaka K, $\mathrm{H}$ irai T, Yasui K, M orimoto T, Kato T, Kito T. 
The prognostic value of preoperative serum levels of the CEA and CA 19-9 in patients with the gastric cancer. Am J Gastroenterol 1996;91:49-53.

12. Nakane $Y, O$ kamura $S$, Akehira K, Boku T, O kusaT, Tanaka K, H ioki K. Correlation of preoperativecarcinoembryonic antigen levels and prognosis of gastric cancer patients. Cancer 1994;73:2703-8.

13. M arelli $D$, Roviello F, DeStefano A, Farnetani $M, G$ arosi L, M essano A, Pinto E. Prognostic significance of CEA and CA 72-4 preoperative serum levels in gastric carcinoma. O ncology 1999 57:55-62.

14. Ishigami S, N atsugoe $S$, H okita S, Che X,
Tokuda K, N akajo A, I washigeH , Tokushige M, Watanabe T, Takao S, Aikou T. Clinical importance of preoperative carcinoembryonic antiigen and carbohydrate antigen 19-9 levels in gastric cancer. J Clin Gastroenterol 2001;32(1):41-4.

15. Kim DY, Kim H R, Shim JH, Park CS, Kim SK, Kim YJ. Significance of serum and tissue carcinoembryonic antigen for the prognosis of gastric carcinoma patients. J Surg O ncol 2000;74:185-92.

16. Imada T, Rino $Y$, Takahashi $M, H$ atori $S$, ShiozawaM , Amano T, Kondo J. Serum CA 199, SLX, SLN and CEA levels of theperipheral and draining venous blood in gastric cancer. H epatogastroenterology 1999;46:2086-90. 